\begin{tabular}{|c|c|c|}
\hline \multirow{3}{*}{$\begin{array}{r}\text { Case Reports in } \\
\text { Gastroenterology }\end{array}$} & \multirow{2}{*}{\multicolumn{2}{|c|}{ Case Rep Gastroenterol 2014;8:13-17 }} \\
\hline & & \\
\hline & $\begin{array}{l}\text { DOI: } 10.1159 / 000358044 \\
\text { Published online: January 10, } 2014\end{array}$ & $\begin{array}{l}\text { ○ } 2014 \text { S. Karger AG, Basel } \\
\text { 1662-0631/14/0081-0013\$39.50/0 } \\
\text { www.karger.com/crg }\end{array}$ \\
\hline & \multicolumn{2}{|c|}{$\begin{array}{l}\text { This is an Open Access article licensed under the terms of the Creative Commons } \\
\text { Attribution-NonCommercial } 3.0 \text { Unported license (CC BY-NC) (www.karger.com/OA } \\
\text { license), applicable to the online version of the article only. Distribution permitted for non } \\
\text { commercial purposes only. }\end{array}$} \\
\hline
\end{tabular}

\title{
Olanzapine and Betamethasone Are Effective for the Treatment of Nausea and Vomiting due to Metastatic Brain Tumors of Rectal Cancer
}

\author{
M. Suzuki K. Komuro K. Ohara \\ Department of Palliative Care, National Hakodate Hospital, Hakodate, Japan
}

\author{
Key Words \\ Olanzapine $\cdot$ Nausea $\cdot$ Vomiting $\cdot$ Brain tumor
}

\begin{abstract}
Brain lesions originating from metastasis of colorectal cancer represent $3-5 \%$ of all brain metastases and are relatively rare. Of all distant metastases of colorectal cancer, those to the liver are detected in $22-29 \%$ of cases, while those to the lungs are detected in $8-18 \%$ of cases. In contrast, brain metastasis is quite rare, with a reported incidence ranging from 0.4 to $1.8 \%$. Treatments for metastatic brain tumors include surgery, radiotherapy, chemotherapy and supportive care with steroids, etc. Untreated patients exhibit a median survival of only approximately 1 month. The choice of treatment for brain metastasis depends on the number of lesions, the patient's general condition, nerve findings and presence of other metastatic lesions. We herein report the case of a 78-year-old male who presented with brain metastases originating from rectal carcinoma. He suffered from nausea, vomiting, anorexia and vertigo during body movement. He received antiemetics, glycerol and whole brain radiation therapy; however, these treatments proved ineffective. Olanzapine therapy was started at a dose of $1.25 \mathrm{mg}$ every night. The persistent nausea disappeared the next day, and the frequency of vomiting subsequently decreased. The patient was able to consume solid food. Olanzapine is an antipsychotic that has recently been used as palliative therapy for refractory nausea and vomiting in patients receiving chemotherapy. We consider that olanzapine was helpful as a means of supportive care for the treatment of nausea and vomiting due to brain metastasis.

(c) 2014 S. Karger AG, Basel
\end{abstract}

Masako Suzuki

Department of Palliative Care

National Hakodate Hospital, 18-16, Kawahara-town

Hakodate-city, Hokkaido 041-8512 (Japan)

E-Mailmasako-s@gol.com 
Suzuki et al.: Olanzapine and Betamethasone Are Effective for the Treatment of Nausea and Vomiting due to Metastatic Brain Tumors of Rectal Cancer

\section{Introduction}

The frequency of brain metastasis of colorectal cancer is reported to be $0.4-1.8 \%$ [1], which is relatively rare. As for the treatment of brain metastasis, surgery, radiotherapy and chemotherapy are often administered, with related symptoms, such as nausea, vomiting, headache and hemiplegia, treated with steroids and glycerol. In one study, the symptoms of $70 \%$ of patients with brain metastases from colorectal carcinoma who received whole brain radiation therapy were improved [2], although the median survival time was only 3-4 months [2, 3]. Nevertheless, some patients continue to experience distressing symptoms. Nausea and vomiting are two potentially unbearable symptoms for patients with advanced cancer receiving palliative care.

We herein report the case of a 78-year-old male with rectal cancer that had metastasized to the brain. He had previously received whole brain radiation therapy, intravenous glycerin and antiemetics, but these treatments were ineffective for the nausea, vomiting and appetite loss. We administered olanzapine before initiating steroid therapy, which was effective in treating the patient's symptoms.

\section{Case Report}

A 78-year-old male presented with nausea, vomiting, anorexia and slight right hemiplegia. He was diagnosed with rectal cancer in August 2007, and laparoscopic low anterior resection was performed. Pathological examination confirmed the diagnosis of rectal adenocarcinoma pSE,N2,M0, stage IIIb. He received adjuvant chemotherapy consisting of oral uracil and tegafur plus leucovorin for 1 year. In November 2008, lung metastases were detected, and the chemotherapy was switched to fluorouracil, levoleucovorin and irinotecan-based chemotherapy (FOLFIRI). In May 2009, lung metastases developed, and the chemotherapy was combined with bevacizumab. However, bevacizumab was discontinued due to angina in February 2011. The lung metastases worsened in January 2012, and the chemotherapy was changed from FOLFIRI to fluorouracil, levoleucovorin and oxaliplatinbased chemotherapy (FOLFOX4). In September 2012, brain imaging using magnetic resonance imaging (MRI) showed multiple brain metastases (maximum size $10 \mathrm{~mm}$ ) in the left lobe with surrounding cerebral edema (fig. 1).

On October 11, 2012 the patient was admitted for nausea, vomiting, anorexia and vertigo during body movement. Right hemiplegia appeared on hospital day 6, and he underwent whole brain radiation therapy with $30 \mathrm{~Gy}$ in 10 fractions starting on hospital day 7 in addition to therapy with glycerol $400 \mathrm{ml}$ daily and the antiemetics metoclopramide and granisetron hydrochloride. The treatment failed to relieve his nausea and vomiting, and he was referred to the department of palliative care on hospital day 34. Treatment with olanzapine was initiated at a dose of $1.25 \mathrm{mg}$ every night. The constant nausea disappeared the next day. The vomiting during body movement decreased from 2-3 times a day to 0-1 times a day, and the patient's appetite increased. However, 6 days after the administration of olanzapine, he developed a sudden intense headache in addition to nausea and vomiting, and right hemiplegia and anarthria rapidly progressed (on hospital day 39). On MRI, the size of the main brain metastatic lesion had increased to $20 \mathrm{~mm}$ and the surrounding cerebral edema had worsened (fig. 2). The patient received betamethasone $4 \mathrm{mg}$ per day in addition to olanzapine $1.25 \mathrm{mg}$. For approximately 3 weeks until death (on hospital day 64), the nausea and vomiting were relieved, without anorexia. However, the sudden periodic intense headaches and paralysis did not improve. 
Suzuki et al.: Olanzapine and Betamethasone Are Effective for the Treatment of Nausea and Vomiting due to Metastatic Brain Tumors of Rectal Cancer

\section{Discussion}

Olanzapine is an atypical antipsychotic that is used to treat schizophrenia and delirium. Recently, the effects of this drug on refractory vomiting during chemotherapy or in patients with advanced cancer have been reported $[4,5]$.

The first-line treatment for intracranial tumors with cerebral edema is dexamethasone; however, the administration of high-dose steroid therapy for long periods has the potential to induce complications, such as infection, hemorrhage of the digestive tract and hyperglycemia. In the present case, the administration of olanzapine before steroid therapy relieved the patient's nausea and vomiting and improved his quality of life.

We found two reports in which olanzapine was found to be effective for nausea and vomiting due to brain metastasis. One case involved a 67-year-old male with esophageal cancer who was undergoing steroid therapy with haloperidol for vomiting. However, his symptoms did not improve, and olanzapine was prescribed at a dose of $5 \mathrm{mg}$ per day, titrated up to $10 \mathrm{mg}$ per day. The patient's vomiting decreased over 10 days [6]. The other case involved a 50-year-old female with lung cancer that had metastasized to the brain who suffered from nausea. In addition to treatment with dexamethasone (2-4 mg orally every day), the administration of multiple antiemetics (including prochlorperazine, promethazine, haloperidol and lorazepam) proved ineffective and overly sedating. Olanzapine monotherapy was initiated at a dose of $2.5 \mathrm{mg}$ every night, titrated up to $5 \mathrm{mg}$ every night, achieving good relief of the nausea without excessive sedation [7]. Therefore, previous reports have shown olanzapine therapy to be helpful when treatment with steroids is unsuccessful.

Olanzapine blocks at dopamine $\left(\mathrm{D}_{1}, \mathrm{D}_{2}, \mathrm{D}_{3}\right.$ and $\left.\mathrm{D}_{4}\right)$, acetylcholine $(\mathrm{Achm})$, histamine $\left(\mathrm{H}_{1}\right)$, serotonin $\left(5-\mathrm{HT}_{2 \mathrm{a}}, 5-\mathrm{HT}_{2 \mathrm{c}}, 5-\mathrm{HT}_{3}\right.$ and $\left.5-\mathrm{HT}_{6}\right)$ and alpha1 adrenergic receptors [7-9]. Nausea and vomiting are stimulated at the vomiting center, which is situated in the medulla oblongata, comprising the reticular formation and nucleus of the tractus solitarius with receptors for neurokinin ( $\mathrm{NK}_{1}$ ), Achm, 5- $\mathrm{HT}_{2,3}$ and $\mathrm{H}_{1}[10]$.

Receptors associated with the neural transmission of vomiting include $\mathrm{D}_{2}, A c h m, \mathrm{H}_{1}$, $5-\mathrm{HT}_{2,3}, \mathrm{NK}$, etc., and nausea and vomiting are triggered by noxious stimulation of the vomiting center directly or indirectly via the gastrointestinal tract $\left(5-\mathrm{HT}_{2}\right)$, cerebral cortex (including multiple receptors that can be triggered by anxiety and mechanoreceptors in the meninges sensitive to changes in intracranial pressure), vestibular region (Achm and $\mathrm{H}_{1}$ ) and chemoreceptor trigger zone. The chemoreceptor trigger zone, located in the area postrema, in the floor of the 4th ventricle has no blood-brain barrier, which enables various drugs, toxins and metabolites to access the site. The chemoreceptor trigger zone also contains $\mathrm{D}_{2}, \mathrm{NK}_{1}$ and serotonin $\left(5-\mathrm{HT}_{2}\right.$ and $\left.5-\mathrm{HT}_{3}\right)$ receptors $[4,10]$. Brain tumors stimulate the vomiting center directly via increased intracranial pressure due to the mass effect, act on the chemoreceptor trigger zone via the secretion of tumor products and induce nausea and vomiting. The interactions between olanzapine and multiple receptors implicated in nausea and vomiting may exert an antiemetic effect.

The effects of olanzapine on anorexia have also been reported $[11,12]$. We consider that the increased appetite observed in our patient was the result of improvements in the control of his nausea and vomiting, although it may also have been due to the appetite promotion effects of olanzapine.

Passik et al. [12] examined three dose levels of olanzapine (2.5, 5 and $10 \mathrm{mg}$ ) in an openlabel pilot study of 15 patients treated for opioid-induced nausea and found olanzapine to be associated with significant reductions in nausea in a dose-dependent fashion. Common side effects reported in patients treated with olanzapine include somnolence, constipation, dizziness, restlessness and weight gain. Previous studies have reported the onset of diabetes 
Suzuki et al.: Olanzapine and Betamethasone Are Effective for the Treatment of Nausea and Vomiting due to Metastatic Brain Tumors of Rectal Cancer

and hyperglycemia [13]. One common side effect is somnolence, as olanzapine is a strong antihistamine of the $\mathrm{H}_{1}$ receptor; therefore, we carefully selected a lower dose of olanzapine. If the patient's intracranial pressure had progressed more slowly, increasing the dose of olanzapine might have been effective for his nausea and vomiting.

Nausea is a very unpleasant symptom, and it is important to relieve nausea early due to the poor prognosis of patients with advanced cancer. In the present case, olanzapine was helpful as a means of supportive care for the treatment of nausea and vomiting due to brain metastasis. However, there are few reported cases regarding the effects of olanzapine on nausea and vomiting induced by brain metastasis, and further accumulation of cases is necessary.

\section{References}

1 Hammoud MA, McCutcheon IE, Elsouki R, Schoppa D, Patt YZ: Colorectal carcinoma and brain metastasis: distribution, treatment, and survival. Ann Surg Oncol 1996;3:453-463.

-2 Amichetti M, Lay G, Dessie M, Orrue S, Farigu R, Farci D, Melis S: Results of whole brain radiation therapy in patients with brain metastases from colorectal carcinoma. Tumori 2005;91:163-167.

-3 Damiens K, Ayoub JPM, Lemieux B, Aubin F, Saliba W, Campeau MP, Tehfe M: Clinical features and course of brain metastases in colorectal cancer: an experience from a single institution. Curr Oncol 2012;19:254-258.

4 Srivastava M, Brito-Dellan N, Davis MP, Leach M, Lagman R: Olanzapine as an antiemetic in refractory nausea and vomiting in advanced Cancer. J Pain Symptom Manage 2003;25:578-582.

5 Navari RM, Nagy CK, Gray SE: The use of olanzapine versus metoclopramide for the treatment of breakthrough chemotherapy-induced nausea and vomiting in patients receiving highly emetogenic chemotherapy. Support Care Cancer 2013;21:1655-1663.

-6 Shinjo T, Okada M: Olanzapine use in cancer patients for refractory vomiting. Gan To Kagaku Ryoho 2006;33:349-352.

7 Jacson WC, Tavernier L: Olanzapine for intractable nausea in palliative care patients. J Palliat Med 2003;6: 251-255.

-8 Bymaster FP, Calligaro DO, Falcone JF, Marsh RD, Moore NA, Tye NC, Seeman P, Wong DT: Radioreceptor binding profile of the atypical antipsychotic olanzapine. Neuropsychopharmacology 1996;14:87-96.

-9 Bymaster FP, Falcone JF, Bauzon D, Kennedy JS, Schenck K, DeLapp NW, Cohen ML: Potent antagonism of 5- $\mathrm{HT}_{3}$ and 5- $\mathrm{HT}_{6}$ receptors by olanzapine. Eur J Pharmacol 2001;430:341-349.

10 Becker DE: Nausea, vomiting, and hiccups: a review of mechanisms and treatment. Anesth Prog 2010;57: 150-157.

11 Navari RM, Brenner MC: Treatment of cancer-related anorexia with olanzapine and megestrol acetate: a randomized trial. Support Care Cancer 2010;18:951-956.

12 Passik SD, Lundberg J, Kirsh KL, Theobald D, Donaghy K, Holtsclaw E, Cooper M, Dugan W: A pilot exploration of the antiemetic activity of olanzapine for the relief of nausea in patients with advanced cancer and Pain. J Pain Symptom Manage 2002;23:526-532.

13 Jin H, Meyer JM, Jeste DV: Phenomenology of and risk factors for new-onset diabetes mellitus and diabetic ketoacidosis associated with atypical antipsychotics: an analysis of 45 published cases. Ann Clin Psychiatry 2002;14:59-64. 


\section{Case Reports in \\ Gastroenterology}

\begin{tabular}{l|l}
\hline Case Rep Gastroenterol 2014;8:13-17 \\
\hline DOI: 10.1159/000358044 & $\begin{array}{l}\text { ○ 2014 S. Karger AG, Basel } \\
\text { www.karger.com/crg }\end{array}$ \\
\hline
\end{tabular}

Suzuki et al.: Olanzapine and Betamethasone Are Effective for the Treatment of Nausea and Vomiting due to Metastatic Brain Tumors of Rectal Cancer

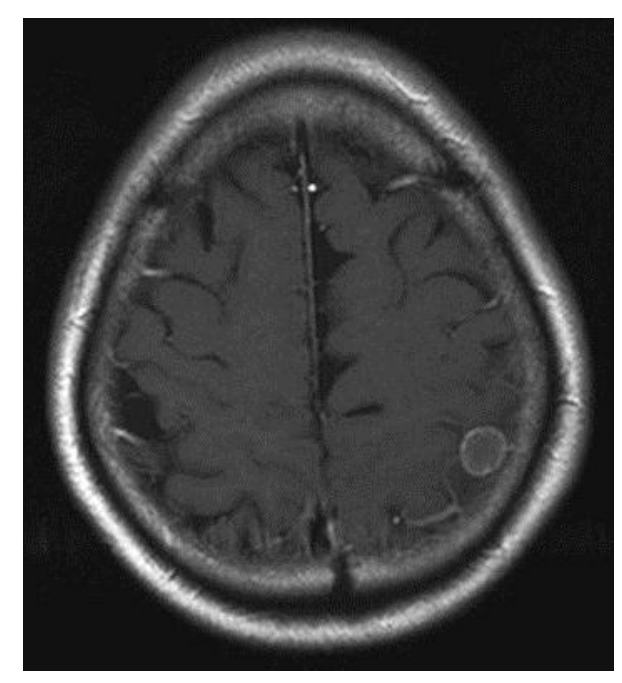

Fig. 1. Axial MRI of the brain showed brain metastasis. The maximum size of the brain metastasis was a tumor in the left lobe measuring $10 \mathrm{~mm}$ in diameter with surrounding cerebral edema.

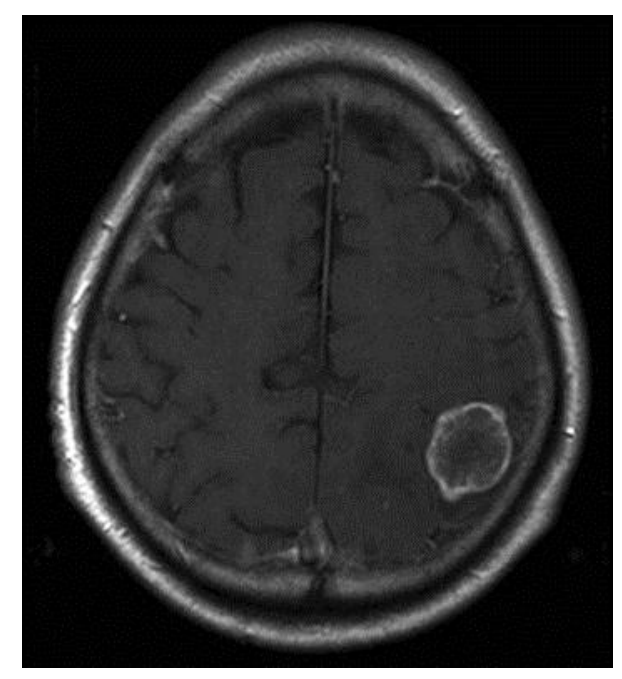

Fig. 2. MRI on hospital day 43. The brain metastasis had increased to $20 \mathrm{~mm}$ in diameter and the surrounding cerebral edema had become worse. 